\title{
Parametric Study of a Long-Duration Energy Storage Using Pumped-Hydro and Carbon Dioxide Transcritical Cycles
}

\author{
Paul Byrne ${ }^{1, *(D)}$ and Pascal Lalanne ${ }^{2}$ (D) \\ 1 Laboratoire Génie Civil Génie Mécanique, University of Rennes, 35000 Rennes, France \\ 2 Hydroclapeyron, Altair, 35800 Dinard, France; pascallalanne@indo.net.id \\ * Correspondence: paul.byrne@univ-rennes1.fr
}

check for updates

Citation: Byrne, P.; Lalanne, P.

Parametric Study of a Long-Duration Energy Storage Using

Pumped-Hydro and Carbon Dioxide Transcritical Cycles. Energies 2021, 14, 4401. https://doi.org/10.3390/ en14154401

Academic Editor: Carlo Roselli

Received: 25 May 2021

Accepted: 20 July 2021

Published: 21 July 2021

Publisher's Note: MDPI stays neutral with regard to jurisdictional claims in published maps and institutional affiliations.

Copyright: (c) 2021 by the authors. Licensee MDPI, Basel, Switzerland. This article is an open access article distributed under the terms and conditions of the Creative Commons Attribution (CC BY) license (https:/ / creativecommons.org/licenses/by/ $4.0 /)$.

\begin{abstract}
The urgent energy transition needs a better penetration of renewable energy in the world's energy mix. The intermittency of renewables requires the use of longer-term storage. The present system uses water displacement, in a lined rock cavern or in an aerial pressurised vessel, as the virtual piston of compressor and expander functions in a carbon dioxide heat pump cycle (HPC) and in an organic transcritical cycle (OTC). Within an impermeable membrane, carbon dioxide is compressed and expanded by filling and emptying pumped-hydro water. Carbon dioxide exchanges heat with two atmospheric thermal storage pits. The hot fluid and ice pits are charged by the HPC when renewable energy becomes available and discharged by the OTC when electricity is needed. A numerical model was built to replicate the system's losses and to calculate its round-trip efficiency (RTE). A subsequent parametric study highlights key parameters for sizing and optimisation. With an expected RTE of around $70 \%$, this $\mathrm{CO}_{2}$ PHES (pumped-hydro electricity storage) coupled with PTES (pumped thermal energy storage) could become a game-changer by allowing the efficient storage of intermittent renewable energy and by integrating with district heating and cooling networks, as required by cities and industry in the future.
\end{abstract}

Keywords: energy storage; pumped hydro; underground pumped hydro; thermo-electrical storage; PTES; heat pump; thermal engine; carbon dioxide; lined rock cavern; round-trip efficiency; global warming potential

\section{Introduction}

In order to limit climate change, many governments have launched energy transition measures. In France, nuclear energy takes benefit of low carbon dioxide emissions compared to thermal plants [1]. However, possible nuclear risks exist, and nuclear wastes have to be dealt with. Renewable energy such as solar or wind energy also emits low amounts of carbon dioxide to the atmosphere. For these resources, their intermittency limits their development. In order to secure the energy supply, nearly the same power from fossil fuels as from renewables will have to be installed or remain available until novel long-duration storage systems are used [1].

Long-duration energy storage systems are the key to the development of more renewable energy systems in the global energy mix. Ram et al. state that the global storage capacity of all durations should be around 64 TWh of electricity plus 40 TWh of thermal energy if the entire energy supply shall depend on renewables by the year 2050 [2]. In the context of growing energy demand, especially for cooling [3], this potential encourages the development of new low-cost energy storage systems.

Figure 1 was built thanks to the literature review that was performed for the present project. It summarises in a single chart the main types of energy storage technologies (coloured rectangles or triangles), according to function (ellipses), power (y-axis) and duration (x-axis). The functions of storage systems selected are the following: stability of the grid, phasing out of power plant peaks, services to micro-grids, addition to intermittent 
renewable energies and seasonal storage. The systems investigated in the literature review are the following: flywheels, electric batteries, flow batteries, pumped hydro energy storage (PHES), compressed air energy systems and advanced adiabatic compressed air energy systems (CAES and AA-CAES), liquid air energy storage (LAES), hydrogen and synthesised fuels. The proposed $\mathrm{CO}_{2}$ PHES coupled with PTES intends to help develop renewable energies with a storage duration from 5 to $500 \mathrm{~h}$. The corresponding boundaries are shown by the red colour in Figure 1.

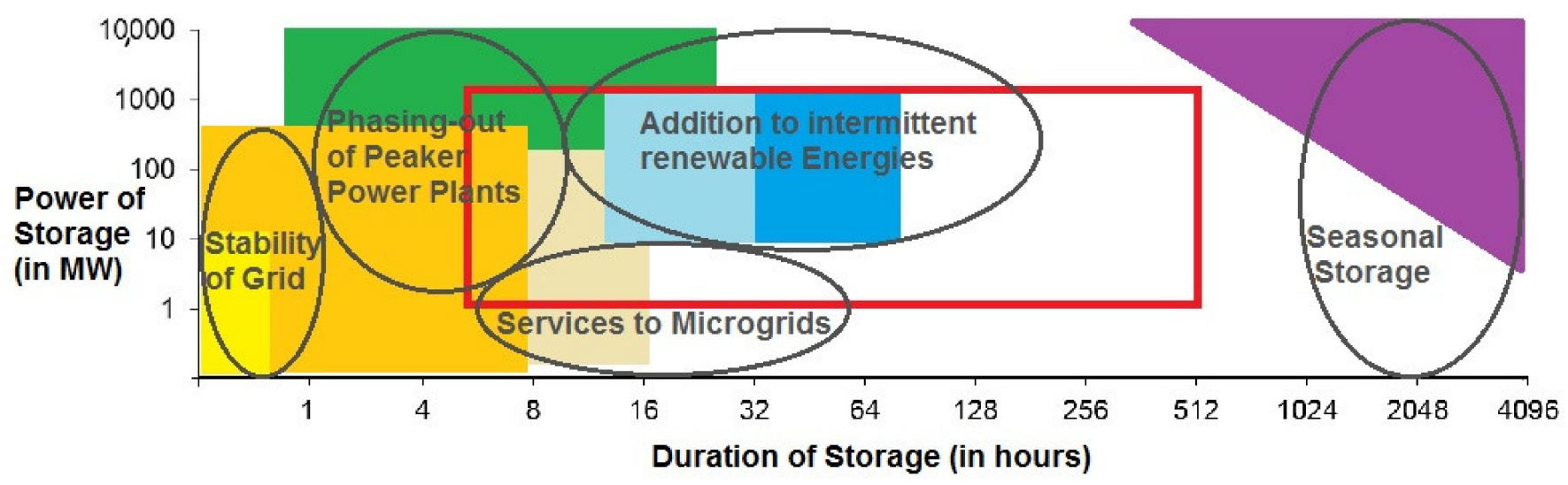

\begin{tabular}{llll|l|l|l}
\hline Flywheels & Batteries & $\begin{array}{l}\text { Flow } \\
\text { Batteries }\end{array}$ & PHES & $\begin{array}{l}\text { CAES \& } \\
\text { AA-CAES }\end{array}$ & LAES & $\begin{array}{l}\text { Hydrogen \& } \\
\text { Synth. Fuels }\end{array}$ \\
\hline
\end{tabular}

Figure 1. Chart of energy storage systems according to function, technology, power and duration.

Table 1 shows the articles reviewed for this study, and the corresponding system characteristics and efficiencies are given. The round trip efficiency (RTE) is the total efficiency of a charging and discharging process defined as the amount of energy released over the amount of energy available.

A flywheel system for utility-scale stationary applications was investigated by Rahman et al. [4]. The high RTE is linked to the short-duration storage, which is out of the target of our study. Electrochemical batteries are also not adapted to long-duration storage. The high embodied carbon consumed for their production and the mining of rare metals can only be compensated by a high number of short-duration storage cycles. Barnhart and Benson used the Energy Stored On Invested indicator (ESOI), defined as the amount of energy that can be stored by a technology divided by the amount of energy required to build that technology [5]. The comparison of ESOI is carried out for lithium-ion (Li-ion), sodium-sulphur ( $\mathrm{NaS}$ ) and lead-acid $(\mathrm{PbA})$ batteries, vanadium redox (VRB) and zinc-bromine ( $\mathrm{ZnBr}$ ) flow batteries, and finally pumped hydro energy storage (PHES) and compressed air energy storage (CAES). Because of high energy costs, the authors conclude that batteries will not play a singular role in providing flexibility for power grids supplied by renewable resources. Therefore, long-duration storage must have a low price and embodied carbon.

PHES is presently the most common technology for the long-duration storage of intermittent energy such as solar and wind. Hunt et al. reviewed the existing pumped storage types [6]. They classify PHES depending on the cycle duration (daily, weekly, seasonal and pluriannual) corresponding to reservoir volumes ranging from 0.001 to $100 \mathrm{~km}^{3}$. They suggest that future PHES should serve long-term and short-term energy storage needs in order to compete with batteries. Many other functions are cited, such as water storage, improvement of water and energy management or reduction of price fluctuations of water and energy.

Cavazzini also studied the connection between PHES and the power grid [7]. One advantage of PHES, among other storage systems, is the possibility of frequency control. However, reversible pumps or turbines presently suffer from unstable behaviour. A fine 
design approach enables overcoming this drawback. Another limit of PHES relies on the scarcity of mountainous sites for installation. Pujades et al. studied an Underground Pumped Hydro Energy Storage (UPHES) in deep mines and open-pit quarries [8]. The number of available appropriate installation sites is also low, and the impact of the UPHES system on the groundwater flow can be important due to the variation in piezometric head and hydraulic diffusivity. Connolly et al. investigated practical operation strategies for PHES by utilising electricity price arbitrage in order to maximise the feasible profit. The authors give typical characteristics of existing PHES facilities reported in Table 1 [9].

Studies about Compressed Air Energy Storage systems (CAES) were recently reviewed by Olabi et al. [10]. According to their study, small-scale CAES power rating can range from $3 \mathrm{~kW}$ to $10 \mathrm{MW}$, while large-scale CAES can supply power up to $1 \mathrm{GW}$. The maximum energy storage capacity is 1 GWh, the RTE is between $40 \%$ and $70 \%$, and the system lifetime is between 20 and 40 years. Tallini et al. presented the economic analysis of a micro-CAES system supplied with photovoltaic (PV) energy [11]. They found a payback period of 5 years for the whole system, including the PV field. Bi et al. presented the analytic model of a combined system of CAES and PHES [12]. The system should benefit from the advantages of CAES, which are a possible high capacity, low construction costs and a long lifespan. However, the authors highlight the irreversible processes due to heat losses during compression and expansion and conclude to an RTE as low as $22 \%$. Besides, Odukomaiya et al. developed a small-size aerial prototype of a near-isothermal compressed gas energy storage system reaching an RTE of $82 \%$ using spray cooling/heating and waste-heat utilisation [13]. The key feature for low process irreversibility and efficient heat loss recovery is the slow-moving piston of their system. This article also provides characteristics of other storage systems through their literature review. These characteristics are reported in Table 1. CAES technology has found another improvement path through the development of Advanced Adiabatic Compressed Air Energy Storage (AA-CAES). Compression and expansion become adiabatic because heat is recovered and provided to supply heating or cooling energy to hospitals, hotels, industries and shopping malls. The by-produced heat, resulting in a higher hybrid efficiency, partly compensates for the low RTE. To our knowledge, no grid-scale AA-CAES is presently available. Dib et al. worked on a system composed of commercial units that are available on the market [14]. By means of simulation, they found a system efficiency of 33.7\%, a Levelised Cost Of Energy (LCOE) as low as $0.25 € / \mathrm{kWh}$ and that the storage pressure had the biggest impact on the total cost. Liquid air energy storage (LAES) is an energy storage technology used for large-scale applications such as district cooling and peak shaving. Kandezi et al. obtained an RTE of $66.32 \%$ and exergy efficiency of $49.75 \%$ [15].

Pumped Thermal Electricity (or Energy) Storage (PTES) is described as a promising solution by Steinmann et al. thanks to its simplicity and low Capex (Capital Expenditure) [16]. Heat and cold energy amounts are produced by a heat pump cycle and stored in thermal pits containing water, glycol-water mixtures, salt hydrates, vegetable oils, sand, boreholes in the rock mass, etc. The discharge process uses a Rankine cycle to produce work convertible into electricity. Mercangöz et al. worked on a PTES using $\mathrm{CO}_{2}$ as the working fluid and achieved an RTE of 51\% for a $1 \mathrm{MW}$ pilot plant [17]. With pumps and turbines having efficiencies between 80 and $90 \%$, they obtained a simulated RTE of $65 \%$ for a $50 \mathrm{MW}$ system operating with sources at $122{ }^{\circ} \mathrm{C}$ and $-3{ }^{\circ} \mathrm{C}$. McTigue et al. present parametric studies of a PTES using argon as a working fluid [18]. They conclude that an RTE of $70 \%$ is conceivable. The principal energy losses are encountered in pumps and turbines. Georgiou et al. proposed a thermo-economic analysis and comparison of PTES and liquid-air electricity storage systems (LAES) using simulation means [19]. They concluded that LAES has lower power and energy capital costs and a lower levelised cost of storage. However, at higher electricity buying prices, PTES seems more competitive than LAES. They finally confirm that pumps and turbines represent the highest part of the Capex. The Siemens Gamesa company expects a total cycle efficiency of $50 \%$ with a storage capacity of $130 \mathrm{MWh}$ for a week [20]. Until now, their pilot plant of the electric thermal 
energy storage system (ETES) in Hamburg-Altenwerder, Germany, reached an RTE of 25\%. Nevertheless, Capex for storage is estimated to be up to ten times lower than the one of electrochemical batteries. Experimental small-scale pilot and demonstration PTES plants recently entered in development. However, no grid scale was proposed for construction so far.

Regarding long-duration as well as seasonal energy storage, Power to Hydrogen and Power to Methane are two field-proven technologies. However, high Capex and low RTE are still key barriers to their full deployment [21].

Aware of the urgency of addressing climate change by increasing the share of solar and wind energy in the global energy mix, Lalanne et al. described in a previous article the concept of an Underground Pumped Hydro Energy Storage (UPHES) for large-scale storage of solar and wind energy [22]. The three proposed directions were: $1-u$ sing shallow high-pressure LRC (Lined Rock Cavern); 2-using a slow-moving $\mathrm{CO}_{2}$ piston at the same pressure as the hydro part of the UPHES (pressure transmission is carried out through a membrane); 3 -relying on inexpensive atmospheric thermal pits for longduration storage. The article concludes that, for a duration of storage of $216 \mathrm{~h}, \mathrm{a} \mathrm{CO}$ UPHES coupled with a PTES could deliver Capex costs as low as USD 20/kWh electrical and USD 4/kWh thermal. The target is an electricity density of 5 to $8 \mathrm{kWh} / \mathrm{m}^{3}$ and a medium-high RTE between $60 \%$ and $70 \%$ while making use of the reliability and efficiency of pumped-hydro equipment.

A pressurised UPHES or PHES seems too expensive for the volumes required in the long-duration storage application. A low-cost solution is the use of large, insulated and atmospheric thermal pits or tanks. The hot pit can contain a hot liquid at a temperature as high as $140{ }^{\circ} \mathrm{C}$, such as the 40,000-200,000 $\mathrm{m}^{3}$ hot water pits used in Denmark for seasonal thermal storage, losing only $0.1 \mathrm{~K}$ per day [23]. The cold pit could contain salt hydrates at a temperature between -10 and $-45^{\circ} \mathrm{C}$.

Table 1. Storage systems characteristics and efficiencies.

\begin{tabular}{|c|c|c|c|c|c|}
\hline System & Article & Power & Energy Storage & RTE & Lifetime \\
\hline Flywheel & Rahman et al. [4] & $20 \mathrm{MW}$ & $5 \mathrm{MWh}$ & $90 \%$ & 15-20 years \\
\hline \multirow[t]{2}{*}{ Batteries } & Barnhart and Benson [5] & Not provided & $4-12 \mathrm{~h}$ & $75-90 \%$ & $3-7$ years \\
\hline & Odukomaiya et al. [13] & kW-MW scale & $180-1800 \mathrm{MJ} / \mathrm{m}^{3}$ & $63-90 \%$ & $3-16$ years \\
\hline \multirow{6}{*}{$\begin{array}{c}\text { Flow batteries } \\
\text { PHES }\end{array}$} & Barnhart and Benson [5] & Not provided & $4-12 \mathrm{~h}$ & $64-71 \%$ & $3-7$ years \\
\hline & Hunt et al. [6] & $100 \mathrm{MW}$ & 1 day-several years & Not provided & Not provided \\
\hline & Cavazzini [7] & $\begin{array}{l}\text { Over } 7400 \mathrm{MW} \\
\text { cumulated } \\
\text { in recent years }\end{array}$ & Not provided & $65-80 \%$ & Not provided \\
\hline & Pujades et al. [8] & Not provided & Up to 2 days & Not provided & Not provided \\
\hline & Connolly et al. [9] & $\begin{array}{l}360 \mathrm{MW} \text { pump } \\
300 \mathrm{MW} \text { turbine }\end{array}$ & $2 \mathrm{GWh}$ & $\begin{array}{c}85 \% \\
\text { (92\% pumping } \\
92 \% \text { generating) }\end{array}$ & 40 years \\
\hline & Odukomaiya et al. [13] & GW scale & $0.72-7.2 \mathrm{MJ} / \mathrm{m}^{3}$ & $65-87 \%$ & $30-50$ years \\
\hline \multirow[t]{3}{*}{ CAES } & Olabi et al. [10] & $3 \mathrm{~kW}-1 \mathrm{GW}$ & $100 \mathrm{kWh}-1 \mathrm{GWh}$ & $40-70 \%$ & 20-40 years \\
\hline & Odukomaiya et al. [13] & kW-GW scale & $7.221 .6+\mathrm{MJ} / \mathrm{m}^{3}$ & $30-70 \%$ & 20-40 years \\
\hline & Tallini et al. [11] & $33-100 \mathrm{~kW}$ & Not provided & Not provided & $\begin{array}{c}\text { Payback period of } \\
5 \text { years }\end{array}$ \\
\hline CAES-PHES & $\begin{array}{l}\text { Bi et al. [12] } \\
\text { Odukomaiya et al. [13] }\end{array}$ & $\begin{array}{l}\text { Not provided } \\
3 \mathrm{~kW}\end{array}$ & $\begin{array}{c}\text { Not provided } \\
2.46-3.59 \mathrm{MJ} / \mathrm{m}^{3}\end{array}$ & $\begin{array}{c}21.7-22.6 \% \\
66-82 \%\end{array}$ & $\begin{array}{l}\text { Long } \\
\text { Not provided }\end{array}$ \\
\hline AA-CAES & Dib et al. [14] & $23.5 \mathrm{~kW}$ & $\begin{array}{c}188 \mathrm{kWh} \\
54.6 \mathrm{MJ} / \mathrm{m}^{3}\end{array}$ & $33.7 \%$ & 20 years \\
\hline \multirow[t]{2}{*}{ LAES } & Kandezi et al. [15] & $5300 \mathrm{~kW}$ & $762 \mathrm{MJ} / \mathrm{m}^{3}$ & $65.7 \%$ & 25 years \\
\hline & Georgiou et al. [19] & $12 \mathrm{MW}$ & $50 \mathrm{MWh}$ & $55 \%$ & 30 years \\
\hline \multirow[t]{5}{*}{ PTES } & Steinmann et al. [16] & Multi-MW & Up to $200,000 \mathrm{~m}^{3}$ & $70 \%$ & 20-30 years \\
\hline & Mercangöz et al. [17] & $50 \mathrm{MW}$ & $1 \mathrm{MWh}$ & $65 \%$ & Not provided \\
\hline & McTigue et al. [18] & $2 \mathrm{MW}$ & $200 \mathrm{MJ} / \mathrm{m}^{3}$ & $70 \%$ & Not provided \\
\hline & Georgiou et al. [19] & $2 \mathrm{MW}$ & $11.5 \mathrm{MWh}$ & $75 \%$ & 30 years \\
\hline & Siemens Gamesa [20] & $100 \mathrm{MW}$ & $130 \mathrm{MWh}$ & $50 \%$ & Not provided \\
\hline $\begin{array}{l}\text { Hydrogen and } \\
\text { synthesised fuels }\end{array}$ & Hu et al. [21] & $7 \mathrm{~kW}-1 \mathrm{MW}$ & $2360-4600 \mathrm{MJ} / \mathrm{m}^{3}$ & $19-45 \%$ & $\begin{array}{c}10 \text { years fuel cell } \\
50 \text { years }\end{array}$ \\
\hline
\end{tabular}


In the light of this literature review, a development of the concept previously published in ref. [22], but for an aerial installation, is proposed in this article. It presents an energy storage system using transcritical $\mathrm{CO}_{2}$ cycles and pumped-hydro technology to produce and store thermal energy in reservoirs for a long-term duration ( 5 to $500 \mathrm{~h}$ ). A model was built using an EES environment (Engineering Equation Solver) [24]. A parametric simulation study carried out with the model helps find an optimal design configuration and identify improvement paths.

\section{System Description}

The system is based on the operations of a heat pump cycle (HPC) for energy storage and an organic transcritical cycle (OTC) for energy use. Figure 2 shows in the EES diagram window the scheme of the system and the carbon dioxide HPC and OTC in a pressureenthalpy diagram. For reasons of simplicity and legibility, control and security devices are not represented in the scheme. A zoom on the $\mathrm{CO}_{2}$ P-h diagram is presented in Figure 3.

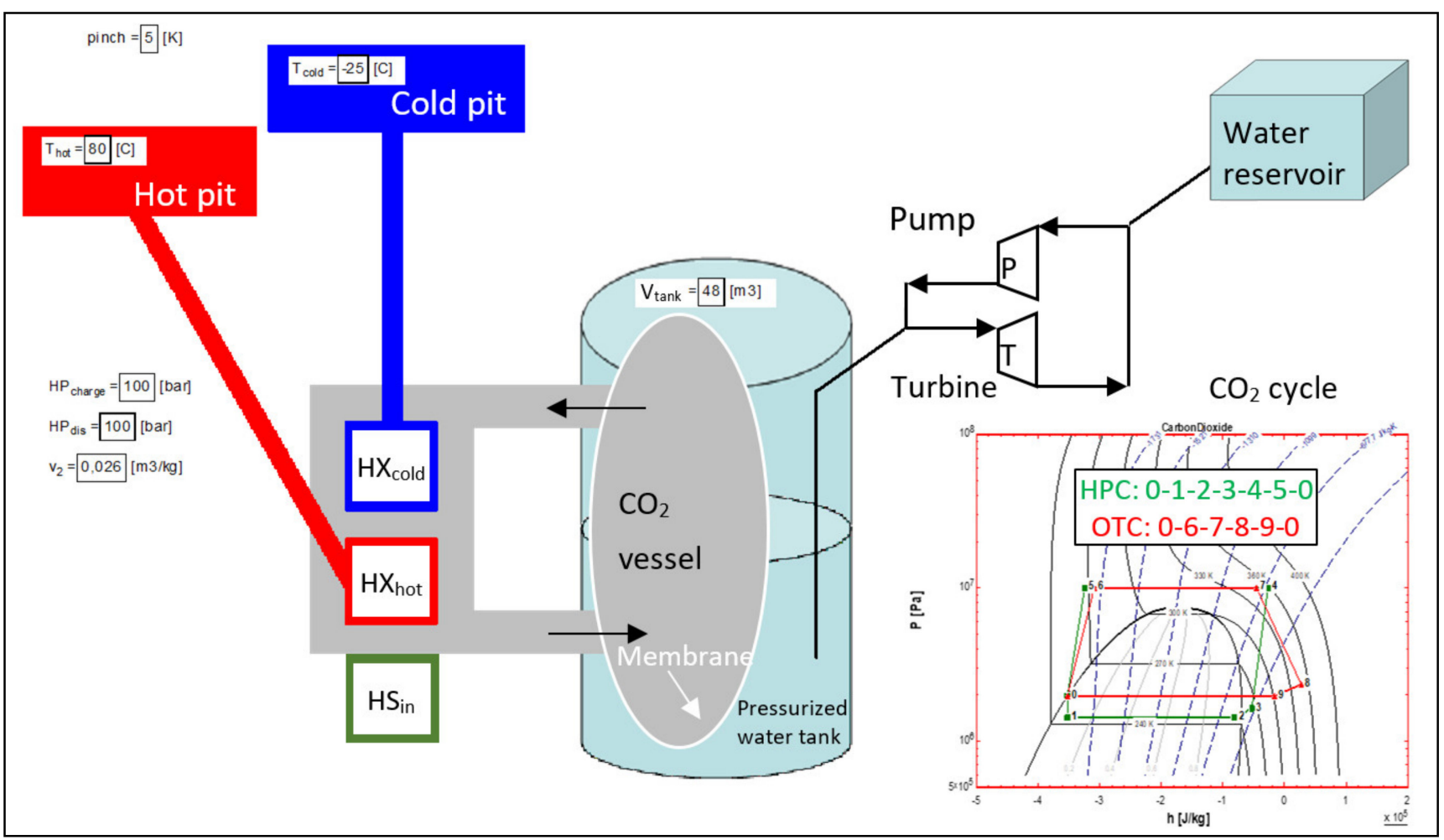

Figure 2. Scheme of the system in the EES environment.

An outdoor water reservoir is connected to a pressurised water tank containing a vessel. Water can be either pumped into the tank or ejected out of the tank through a turbine. A membrane providing absolute tightness between carbon dioxide and water is allowed to retract and expand depending on the water amount within the tank. In the $\mathrm{HPC}$, the compression of $\mathrm{CO}_{2}$ consumes renewable electricity while hot and cold pits store thermal energy. The energy for compression may come from any renewable energy source (solar, wind, etc.). In the OTC, the thermal energy previously produced and stored is used to expand the $\mathrm{CO}_{2}$ and to push on water through the membrane. The water flows through a turbine producing mechanical work and eventually electricity. Thermal energy produced in the hot and cold pits can also be directly consumed whenever needed. An ancillary internal heat storage is used in HPC and OTC to store thermal energy during some part of the cycle and to return this energy in another part of the cycle. The details are given for each cycle in the next section. 


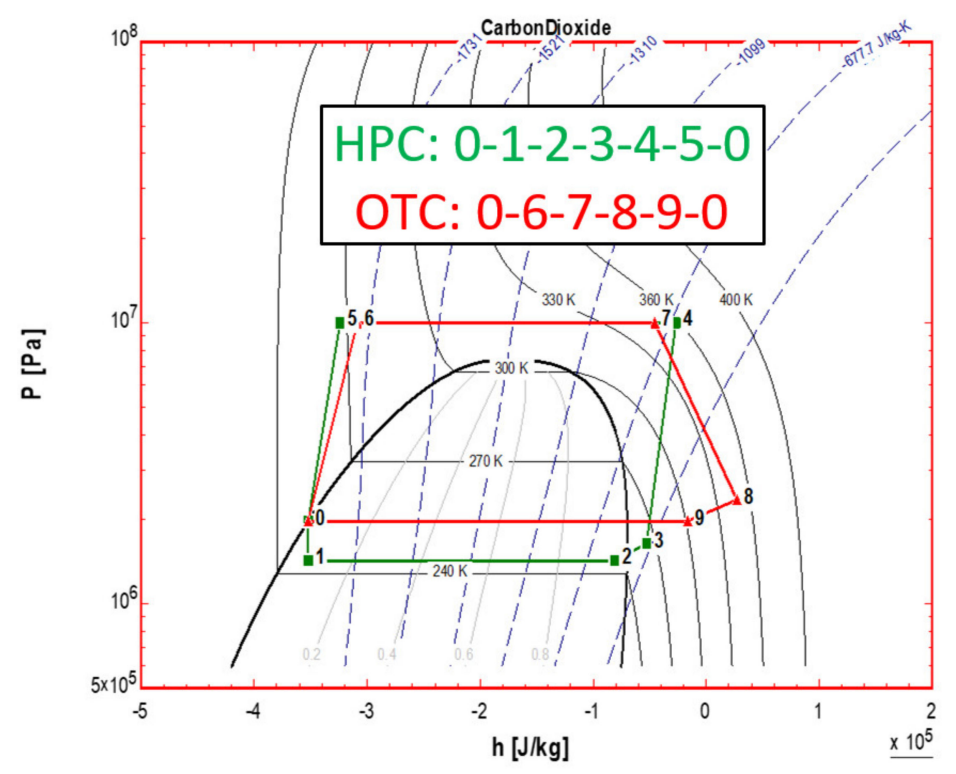

Figure 3. Zoom on the $\mathrm{CO}_{2} \mathrm{P}-\mathrm{h}$ diagram.

\subsection{Heat Pump Cycle}

The HPC corresponds to the green cycle in Figure 3 through points 1 to 5 . The $\mathrm{CO}_{2}$ cycle starts at point $0 . \mathrm{CO}_{2}$ is in a liquid state, and the membrane is completely retracted. Point 0 temperature is equal to the cold pit temperature plus the temperature pinch. The system starts at low pressure at point 0 by opening an electronic valve (not shown in Figure 2) that lets the water flow through the turbine. The cycle is composed of the following transformations:

- From point 0 to point $1, \mathrm{CO}_{2}$ undergoes an isenthalpic expansion by letting water out of the pressurised water tank until the $\mathrm{CO}_{2}$ temperature reaches the cold pit temperature minus the temperature pinch;

- From point 1 to point 2, more water is expelled from the pressurised tank. $\mathrm{CO}_{2}$ is circulated in the cold heat exchanger to store cold energy in the cold pit until the membrane is completely inflated;

- From point 2 to point $3, \mathrm{CO}_{2}$ recovers heat from the internal heat storage $\mathrm{HS}_{\text {in }}$;

- From point 3 to point $4, \mathrm{CO}_{2}$ is compressed by using the water pump to fill up the pressurised water tank. The high pressure and a temperature equal to the one of the hot pit plus the temperature pinch define point 4;

- From point 4 to point $5, \mathrm{CO}_{2}$ undergoes an isobaric compression thanks to the pressurised tank filling. The hot pit is designed as being thermally stratified. The heat produced during this compression is transferred to different heights of the hot pit depending on the evolution of the $\mathrm{CO}_{2}$ temperature;

- From point 5 to point $0, \mathrm{CO}_{2}$ stores heat in the internal heat storage $\mathrm{HS}_{\text {in }}$.

\subsection{Organic Transcritical Cycle}

The OTC corresponds to the red cycle in Figure 3 through points 6 to 9. The $\mathrm{CO}_{2}$ cycle also starts at point 0 :

- From point 0 to point 6 , heat is recovered from the ancillary internal heat storage;

- From point 6 to point 7 , heat from the hot pit is gradually transferred to the $\mathrm{CO}_{2}$, undergoing an expansion. Water is ejected from the tank and flows through the electrical turbine, generating work. Point 7 is defined by a temperature equal to the one of the hot pit minus the temperature pinch;

- From point 7 to point $8, \mathrm{CO}_{2}$ expansion continues until the maximum specific volume is reached;

- $\quad$ From point 8 to point 9 , heat is stored in the ancillary internal heat storage; 
- From point 9 to point $0, \mathrm{CO}_{2}$ is condensed using cold energy from the cold pit.

\subsection{Key Performance Indicators}

The key performance indicators are the coefficients of performance $(C O P)$ in the heat pump cycle and the round-trip efficiency (RTE, $\eta_{r t}$ ) following Equations (1)-(4). Three positive COPs can be defined depending on the utility of thermal energy. The enthalpy amounts are positively counted when energy is gained by the refrigerant.

$$
\begin{gathered}
C O P_{h}=\frac{-\Delta H_{4-5}}{W_{\text {pump }}} \\
C O P_{c}=\frac{\Delta H_{1-2}}{W_{\text {pump }}} \\
C O P_{h \& c}=C O P_{h}+C O P_{c} \\
\eta_{r t}=\frac{W_{\text {turbine }} \cdot f_{u b}}{W_{\text {pump }}+W_{\text {filling }} \cdot f_{u b}}
\end{gathered}
$$

In Equation (4), the round trip efficiency shows an unbalance factor $f_{u b}$ that takes into account the difference of heat exchanged with hot and cold pits in HPC and OTC. The unbalance factor (Equation (5)) is the minimum value between the unbalance factors of exchanges with hot pit (Equation (6)) and with cold pit (Equation (7)).

$$
\begin{gathered}
f_{u b}=\min \left(f_{u b, h} ; f_{u b, c}\right) \\
f_{u b, h}=\frac{-\Delta H_{1-2}}{\Delta H_{9-0}} \\
f_{u b, c}=\frac{-\Delta H_{3-4}-\Delta H_{4-5}}{\Delta H_{6-7}+\Delta H_{7-8}}
\end{gathered}
$$

The presence of these unbalance heat transfers implies that during a charge-anddischarge sequence, some heat is lost. The heat loss is given by Equation (8). As for the unbalance factor, the maximum depends on which cycle has the higher thermal energy exchange.

$$
Q_{\text {loss }}=\max \left(\Delta H_{9-0}+\Delta H_{1-2} ; \Delta H_{6-7}+\Delta H_{7-8}+\Delta H_{3-4}+\Delta H_{4-5}\right)
$$

\subsection{System Pre-Sizing and Specifications}

Pump and turbine are assumed at a rated power of $1 \mathrm{MW}$ and at a mechanical efficiency of 0.9 . The pressurised tank volume is estimated to $50 \mathrm{~m}^{3}$ so that pumping and expanding operations last around $5 \mathrm{~min}$. The tank volume has no impact on the round trip efficiency and on the COP of the system.

The parameters allowed to fluctuate in this work are the hot and cold pit temperatures, the high-side pressure of HPC and of OTC cycles and the temperature pinch, assumed identical in all heat exchangers and in the ancillary internal heat storages. The low-side pressure relies on the cold pit temperature and on the temperature pinch. The melting temperature of a eutectic salt mixture of ethylene glycol, sodium formate and water with a $1-1-8$ weight proportion is $-25^{\circ} \mathrm{C}$. Table 1 shows the variables of the parametric study, their default value and the interval of variation. When a variable fluctuates, other variables are kept constant at the default value.

The fact that HPC and OTC cycles have a common starting point (point 0 ) facilitates the calculation of the round trip efficiency. All thermal losses at heat exchangers are neglected. High-side pressures are assumed equal in both cycles. Indeed, it seems convenient to operate with the same high-side pressure for technological reasons. Other publications using HPC and OTC systems also use the same high-side pressure for both cycles [25,26]. 


\section{Results and Discussion}

Figures 4-7 show the evolutions of heating COP, cooling COP, simultaneous heating and cooling COP and round trip efficiency. The COPs refer to the left axis and the RTE to the right axis. When one parameter is varied, the other ones are kept constant to the default value given in Table 2.

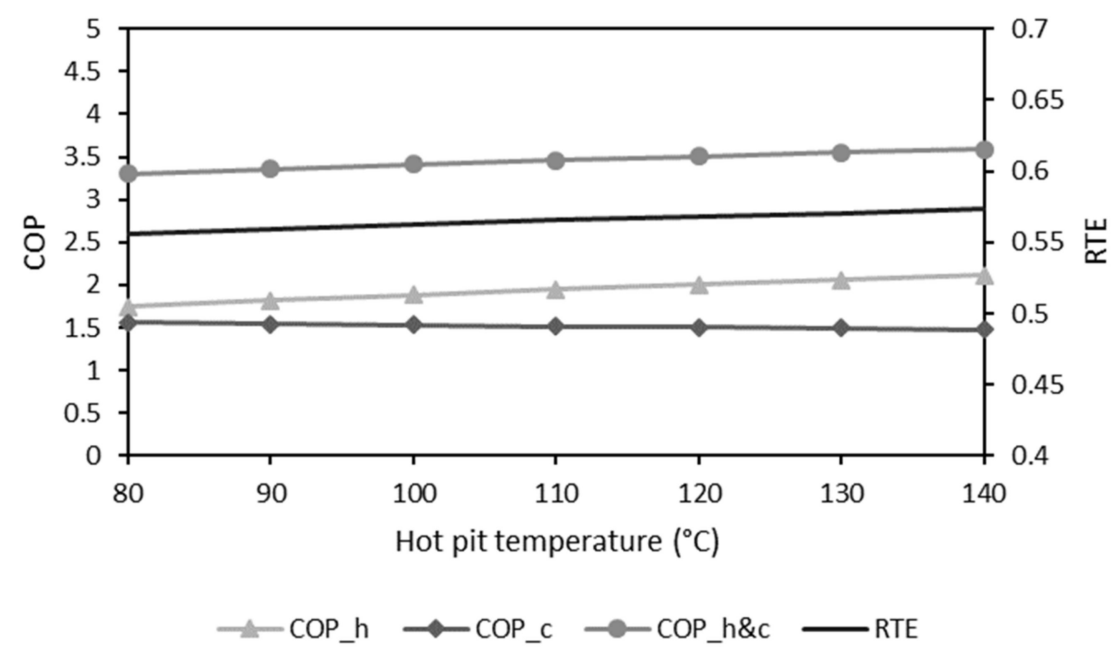

Figure 4. Evolutions of COP depending on hot pit temperature.

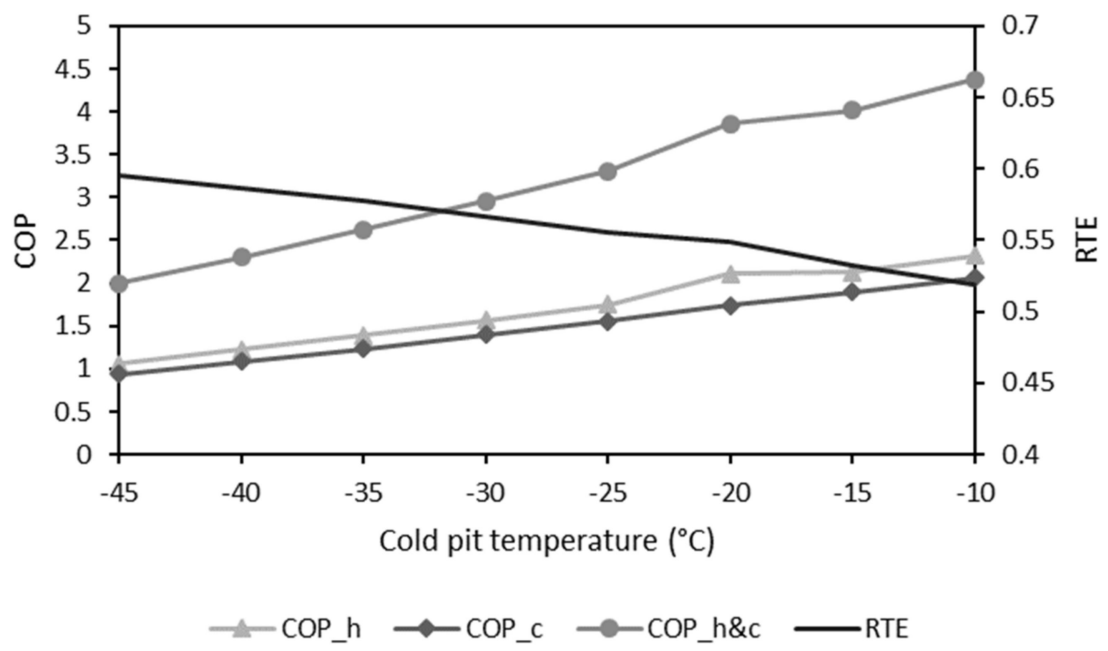

Figure 5. Evolutions of COP depending on cold pit temperature.

Increasing the hot pit temperature up to $140{ }^{\circ} \mathrm{C}$ is possible using thermal oils (Figure 4). However, near $140{ }^{\circ} \mathrm{C}$, limitations appear in regards to temperature resistance for polymer materials (membrane). The hot pit temperature influences favourably all key performance indicators except the cooling COP. On the interval from 80 to $140{ }^{\circ} \mathrm{C}$, the relative variations are $20.8 \%,-4.9 \%, 8.7 \%$ and $3.1 \%$ for $\mathrm{COP}_{\mathrm{h}}, \mathrm{COP}_{\mathrm{c}}, \mathrm{COP}_{\mathrm{h} \& \mathrm{c}}$ and $\eta_{\mathrm{rt}}$, respectively.

Figure 5 shows the upward and downward evolutions with respect to the default value of $-25{ }^{\circ} \mathrm{C}$. Decreasing the cold pit temperature from $-25^{\circ} \mathrm{C}$ (default value) down to $-45{ }^{\circ} \mathrm{C}$ produces an RTE increase of $7.1 \%$ but a COP decrease of around $40 \%$. A temperature of $-45{ }^{\circ} \mathrm{C}$ is achievable using specific salt hydrates. Increasing the cold pit temperature from $-25{ }^{\circ} \mathrm{C}$ up to $-10{ }^{\circ} \mathrm{C}$ decreases the RTE by $-6.6 \%$ and increases the COPs by around 33\%. Therefore, the optimisation of the system will depend on the preferred criteria between work recovery and COP maximisation. 


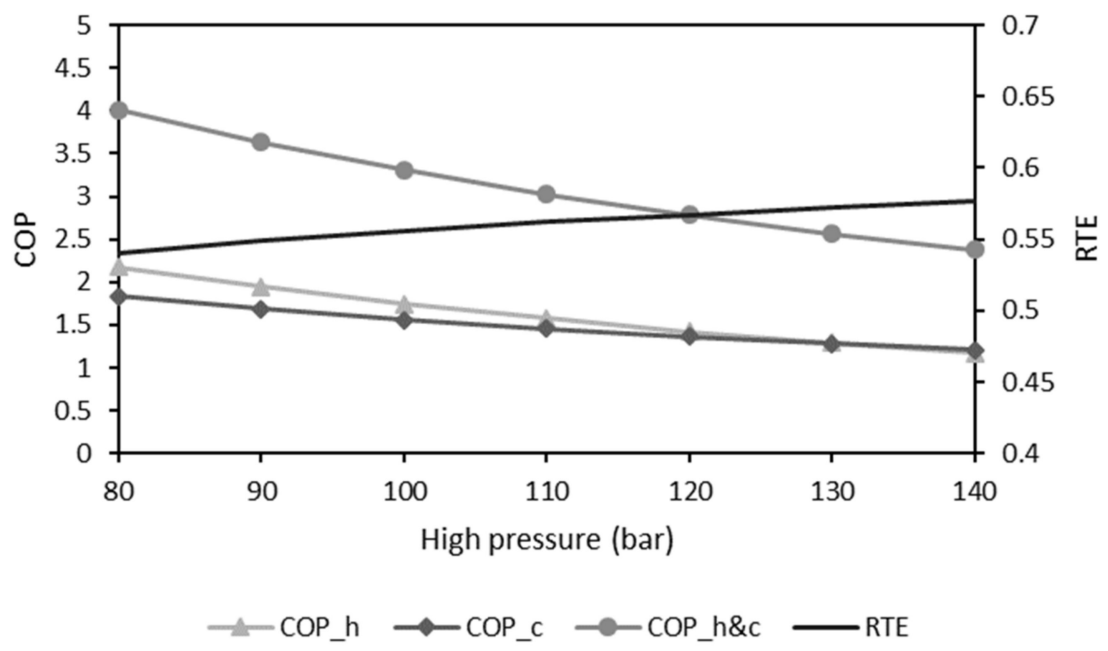

Figure 6. Evolutions of COP depending on high pressure.

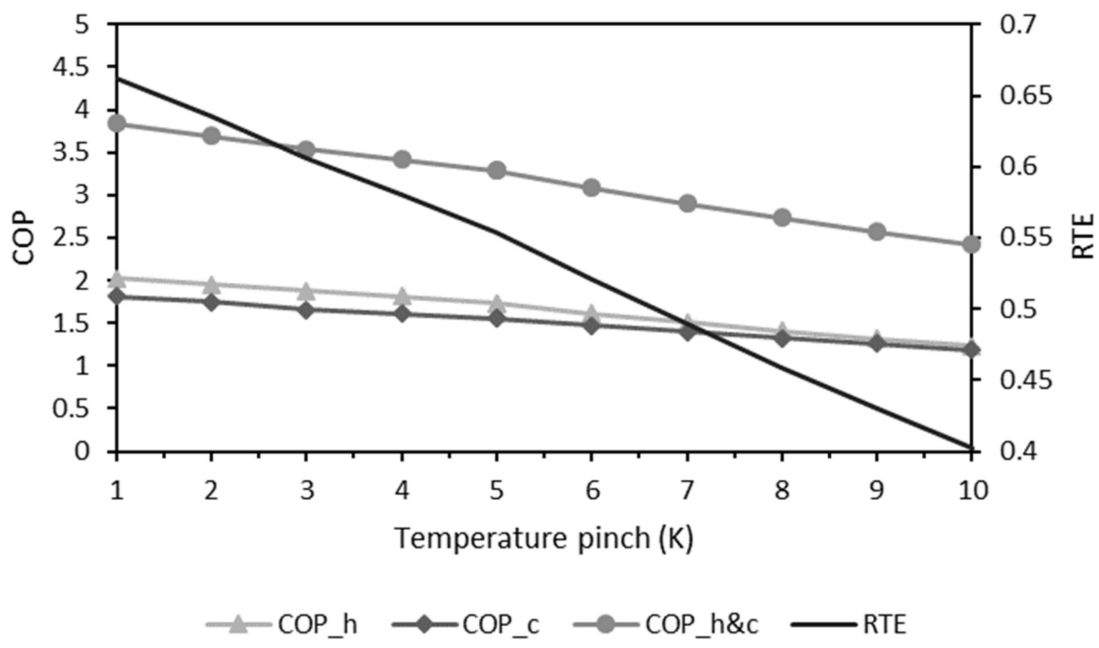

Figure 7. Evolutions of COP depending on temperature pinch.

Table 2. Variables of the parametric study.

\begin{tabular}{ccc}
\hline Variable & Default Value & Interval \\
\hline Hot pit temperature & $80{ }^{\circ} \mathrm{C}$ & 80 to $140{ }^{\circ} \mathrm{C}$ \\
Cold pit temperature & $-25{ }^{\circ} \mathrm{C}$ & -45 to $-10{ }^{\circ} \mathrm{C}$ \\
High-side pressure & $100 \mathrm{bar}$ & 80 to $140 \mathrm{bar}$ \\
Temperature pinch & $5 \mathrm{~K}$ & 2 to $10 \mathrm{~K}$ \\
\hline
\end{tabular}

Figure 6 shows the evolution of the key performance indicators depending on the increase of the high-side pressure up to 140 bar. Raising the high-side pressure triggers a decrease of around $40 \%$ of COPs and an increase of $6.7 \%$ of the round trip efficiency.

Figure 7 shows the impact of the temperature pinch variation. Decreasing the temperature pinch of all heat exchangers simultaneously from $5 \mathrm{~K}$ to $1 \mathrm{~K}$ would enable to gain around $17 \%$ on COP values and $19.6 \%$ on RTE. However, temperature pinches of $1 \mathrm{~K}$ are hardly achievable without oversizing heat exchangers and generating high additional costs. A temperature pinch of $2 \mathrm{~K}$ appears as a desirable techno-economical compromise. For a $2 \mathrm{~K}$ temperature pinch, improvements reach $12.5 \%$ for COPs and $14.7 \%$ for RTE. Increasing temperature pinches dramatically decrease key performance indicators.

Two optimal operating configurations were finally tested for the highest COPs and RTE separately. The optimal values are reported in Table 3. The hot pit temperature increase 
has a positive impact on both COPs and RTE, the selected temperature being $140{ }^{\circ} \mathrm{C}$. The impact is more complex on the low-side pressure. An elevated cold pit temperature ensures a high evaporating pressure. When combined with a lower high-side pressure, it ensures higher COPs but a lower RTE. Therefore, the optimal configuration for high RTE is a low cold pit temperature and the highest possible pressure. As explained before, a temperature pinch of $2 \mathrm{~K}$ is chosen because it reasonably appears more achievable than a pinch of $1 \mathrm{~K}$.

Table 3. Optimal values of variables.

\begin{tabular}{ccc}
\hline Variable & Optimal Value for High COP & Optimal Value for High RTE \\
\hline Hot pit temperature & $140{ }^{\circ} \mathrm{C}$ & $140{ }^{\circ} \mathrm{C}$ \\
Cold pit temperature & $-10{ }^{\circ} \mathrm{C}$ & $-45^{\circ} \mathrm{C}$ \\
High-side pressure & $80 \mathrm{bar}$ & $140 \mathrm{bar}$ \\
Temperature pinch & $2 \mathrm{~K}$ & $2 \mathrm{~K}$ \\
\hline
\end{tabular}

Table 4 reports the key performance indicators in both optimal configurations compared to the base case, in which the parameters correspond to the default values in Table 2. In the COP-optimal simulation, COPs highly increase, and RTE slightly increases. The optimal COP is equal to 5.274. When maximising the RTE, the COPs show a dramatic decrease. To remain in a dimensionless comparison, the heat loss is evaluated with respect to the mechanical energy produced by the turbine. The decrease of heat loss is highly correlated to temperature pinch reduction. The highest RTE is equal to 0.712 , which is among the highest values obtained by other researchers reported in Table 1 for PTES. However, real-scale systems show lower RTE values [20]. The modelled system is considered a perfect environment. The frame of the study is here restricted to the thermodynamic system. Hot and cold pits and internal heat storage are considered black boxes. The exergy losses associated with the heat transfer between the $\mathrm{CO}_{2}$ and the storage fluids were assumed perfect. To our knowledge, no issues were reported on the impact of $\mathrm{CO}_{2}$ on piping. The heat losses are neglected due to an assumed high thermal insulation. Pit temperature variations are considered negligible because of their assumed sufficiently large volume. Pressure drops are neglected due to assumed low flow velocities. Pump and turbine efficiencies are assumed equal to the achievable value of 0.9 . Even though additional heat or mechanical losses should appear in the real system, they could be minimised to negligible values with careful design, production and maintenance. The $1 \mathrm{MW}$ system is intended to be implemented on an industrial site where renewable energy is produced and where heating or cooling energy is needed. However, the concept can be extended to higher powers by increasing the capacities or multiplying the mechanical devices.

Table 4. Key performance indicators for optimal configuration.

\begin{tabular}{cccc}
\hline Indicator & $\begin{array}{c}\text { Default } \\
\text { Configuration }\end{array}$ & $\begin{array}{c}\text { Optimal Value for } \\
\text { High COP }\end{array}$ & $\begin{array}{c}\text { Optimal Value for } \\
\text { High RTE }\end{array}$ \\
\hline $\mathrm{COP}_{\mathrm{h}}$ & 1.746 & 3.138 & 1.027 \\
$\mathrm{COP}_{\mathrm{c}}$ & 1.559 & 2.136 & 0.775 \\
$\mathrm{COP}_{\mathrm{h} \& \mathrm{c}}$ & 3.305 & 5.274 & 1.803 \\
$\mathrm{RTE}$ & 0.556 & 0.610 & 0.712 \\
$Q_{\text {loss }} / \mathrm{W}_{\text {turbine }}$ & $40.3 \%$ & $18.1 \%$ & $7.4 \%$ \\
\hline
\end{tabular}

\section{Conclusions}

This article presents innovative long-duration energy storage using pumped-hydro and carbon dioxide transcritical cycles. A heat pump cycle (HPC) produces and stores heating and cooling energy, and an organic transcritical cycle (OTC) produces work from the previously-stored thermal energy.

A model was built with an equation solver. It does not require the implementation of any component whose characteristics depend on time. The simulations show good 
results in terms of coefficient of performance for heating, cooling simultaneous heating and cooling, and round trip efficiency. Optimal parameters change depending on the use of energy for mechanical or for thermal purposes. The highest heating and cooling COP is 5.274 . The highest RTE is $71.2 \%$. Within the given intervals limited by technological issues, the most influential parameter among the ones tested is the temperature pinch. This parameter will be very important to monitor during the design of a future prototype.

The thermodynamic cycles (HPC and OTC) used in this specific system display the following attractive features:

- Superheating or subcooling is unnecessary. There is no irreversibility linked to these transformations;

- An isothermal compression can be achieved thanks to the availability of significant heat exchanges during the $\mathrm{CO}_{2}$ multiphasic volume variation.

High pressures, starting points and expansion limits can be different in HPC and OTC and can lead to higher efficiency.

Limitations and issues principally relate to heat exchangers, demanding oversizing to allow low-temperature pinches. Thermal storage hot and cold pits and the internal heat storage tank should be designed finely in order to keep the heat losses to very low levels, such as the ones adopted in the black box model used in the present study. Heat exchangers must also be well sequenced to transfer internal heat among different parts of the HPC cycles as well as of the OTC cycles. The heat transfers between $\mathrm{CO}_{2}$ and the storage fluids will be addressed in another study devoted to more practical issues linked to prototyping. Another issue will rely on the starting and stopping sequences.

Thanks to the good COP at a high temperature, the system is able to produce hightemperature heat for industrial needs while other heat pumps cannot. In the field of refrigeration, it is a heat pump for simultaneous heating and cooling, also allowing an attractive COP at low temperatures. If the cooling and heating demands are not balanced, another heat exchange with ambient air or another free source should be considered in the system layout.

While storing electricity for long-duration, the relatively moderate operating temperatures provide this system with the opportunity to lower the carbon intensity of the heating and cooling demands of industry (organic: food, pharmaceuticals, cosmetics, paper, rubber and fine chemicals (polymers)) and of commercial and collective residential buildings. In the future, energy policy makers should regulate the implementation of such energy storage systems. Indeed, if they were to develop, they could have an impact on energy networks and the energy production system.

Author Contributions: Conceptualisation, P.L.; methodology, P.L. and P.B.; software, P.B.; validation, P.B.; writing, P.B. and P.L. All authors have read and agreed to the published version of the manuscript.

Funding: This research received no external funding.

Conflicts of Interest: The authors declare no conflict of interest.

$\begin{array}{ll}\text { Nomenclature } \\ \text { Latin letters: } \\ \text { COP } & \text { Coefficient of performance } \\ \mathrm{H} & \text { Enthalpy }(\mathrm{J}) \\ \mathrm{Q} & \text { Thermal energy }(\mathrm{J}) \\ \mathrm{W} & \text { Work }(\mathrm{J}) \\ \mathrm{f} & \text { Factor }\end{array}$




$\begin{array}{ll}\text { Greek letters: } & \\ \Delta & \text { Variation } \\ \eta & \text { Efficiency } \\ \text { Subscripts: } & \\ \text { c } & \text { cooling } \\ \text { h } & \text { heating } \\ \text { h\&c } & \text { simultaneous heating and cooling } \\ \text { ub } & \text { unbalance }\end{array}$

\section{References}

1. Bellal, A. Environnement et Energie, Comprendre Pour Débattre et Agir; Le Temps Des Cerises: Montreuil, France, 2016; ISBN 9782370710925.

2. Ram, M.; Bogdanov, D.; Aghahosseini, A.; Gulagi, A.; Oyewo, A.S.; Child, M.; Caldera, U.; Sadovskaia, K.; Farfan, J.; Barbosa, L.S.N.S.; et al. Global Energy System Based on 100\% Renewable Energy-Energy Transition in Europe Across Power, Heat, Transport and Desalination Sectors; Lappeenranta University of Technology Research Reports 89; LUT University: Lappeenranta, Finland; Energy Watch Group: Berlin, Germany, 2018; ISBN 978-952-335-329-9; ISSN 2243-3376.

3. International Energy Agency. The Future of Cooling; OECD: Paris, France, 2018.

4. Rahman, M.M.; Gemechu, E.; Oni, A.O.; Kumar, A. The development of a techno-economic model for the assessment of the cost of flywheel energy storage systems for utility-scale stationary applications. Sustain. Energy Technol. Assess. 2021, 47, 101382.

5. Barnhart, C.J.; Benson, S.M. On the importance of reducing the energetic and material demands of electrical energy storage. Energy Environ. Sci. 2013, 6, 1083-1092. [CrossRef]

6. Hunt, J.D.; Zakeri, B.; Lopes, R.; Barbosa, P.S.F.; Nascimento, A.; Castro, N.J.D.; Brandão, R.; Schneider, P.S.; Wada, Y. Existing and new arrangements of pumped-hydro storage plants. Renew. Sustain. Energy Rev. 2020, 129, 109914. [CrossRef]

7. Cavazzini, G.; Houdeline, J.B.; Pavesi, G.; Teller, O.; Ardizzon, G. Unstable behaviour of pump-turbines and its effects on power regulation capacity of pumped-hydro energy storage plants. Renew. Sustain. Energy Rev. 2018, 94, 399-409. [CrossRef]

8. Pujades, E.; Willems, T.; Bodeux, S.; Orban, P.; Dassargues, A. Underground pumped storage hydroelectricity using abandoned works (deep mines or open pits) and the impact on groundwater flow. Hydrogeol. J. 2016, 24, 1531-1546. [CrossRef]

9. Connolly, D.; Lund, H.; Finn, P.; Mathiesen, B.V.; Leahy, M. Practical operation strategies for pumped hydroelectric energy storage (PHES) utilising electricity price arbitrage. Energy Policy 2011, 39, 4189-4196. [CrossRef]

10. Olabi, A.G.; Wilberforce, T.; Ramadan, M.; Abdelkareem, M.A.; Alami, A.H. Compressed air energy storage systems: Components and operating parameters-A review. J. Energy Storage 2021, 34, 102000. [CrossRef]

11. Tallini, A.; Vallati, A.; Cedola, L. Applications of micro-CAES systems: Energy and economic analysis. Energy Procedia 2015, 82, 797-804. [CrossRef]

12. Bi, J.; Jiang, T.; Chen, W.; Ma, X. Research on storage capacity of compressed air pumped hydro energy storage equipment. Energy Power Eng. 2013, 5, 26-30. [CrossRef]

13. Odukomaiya, A.; Abu-Heiba, A.; Gluesenkamp, K.R.; Abdelaziz, O.; Jackson, R.K.; Daniel, C.; Graham, S.; Momen, A.M. Thermal analysis of near-isothermal compressed gas energy storage system. Appl. Energy 2016, 179, 948-960. [CrossRef]

14. Dib, G.; Haberschill, P.; Rullière, R.; Perroit, Q.; Davies, S.; Revellin, R. Thermodynamic simulation of a micro advanced adiabatic compressed air energy storage for building application. Appl. Energy 2020, 260, 114248. [CrossRef]

15. Kandezi, M.S.; Naeenian, S.M.M. Investigation of an efficient and green system based on liquid air energy storage (LAES) for district cooling and peak shaving: Energy and exergy analyses. Sustain. Energy Technol. Assess. 2021, 47, 101396.

16. Steinmann, W.D.; Bauer, D.; Jockenhöfer, H.; Johnson, M. Pumped thermal energy storage (PTES) as smart sector-coupling technology for heat and electricity. Energy 2019, 183, 185-190. [CrossRef]

17. Mercangöz, M.; Hemrle, J.; Kaufmann, L.; Z'Graggen, A.; Ohler, C. Electrothermal energy storage with transcritical $\mathrm{CO}_{2}$ cycles. Energy 2012, 45, 407-415. [CrossRef]

18. McTigue, J.D.; White, A.J.; Markides, C.N. Parametric studies and optimisation of pumped thermal electricity storage. Appl. Energy 2015, 137, 800-811. [CrossRef]

19. Georgiou, S.; Shah, N.; Markides, C.N. A thermo-economic analysis and comparison of pumped-thermal and liquid-air electricity storage systems. Appl. Energy 2018, 226, 1119-1133. [CrossRef]

20. Siemens-Gamesa Electric Thermal Energy Storage. Available online: https://deepresource.wordpress.com/2019/06/17/siemensgamesa-electric-thermal-energy-storage (accessed on 17 October 2020).

21. Hu, G.; Chen, C.; Lu, H.T.; Wu, Y.; Liu, C.; Tao, L.; Men, Y.; He, G.; Li, K.G. A review of technical advances, barriers, and solutions in the Power to Hydrogen (P2H) roadmap. Engineering 2020, 6, 1364-1380. [CrossRef]

22. Lalanne, P.; Byrne, P. Large-scale pumped thermal electricity storages-Converting energy using shallow lined rock caverns, carbon dioxide and underground pumped-hydro. Appl. Sci. 2019, 9, 4150. [CrossRef]

23. Guddat, M. Chapter 140 Seasonal Heat Storage. In Technology Data-Energy Storage; Danish Energy Agency and Energinet: Copenhagen, Denmark, 2018.

24. Klein, S.A. Engineering Equation Solver, @1992-2020; Academic Professional Version V10.834-3D; F-Chart Software, LLC: Madison, WI, USA, 2020. 
25. Sanz Garcia, L.; Jacquemoud, E.; Jenny, P. Thermo-economic heat exchanger optimization for electro-thermal energy storage based on transcritical $\mathrm{CO}_{2}$ cycles. In Proceedings of the 3rd European Supercritical $\mathrm{CO}_{2}$ Conference, Paris, France, 19-20 September 2019.

26. Aghagoli, A.; Sorin, M. CFD modelling and exergy analysis of a heat pump cycle with Tesla turbine using $\mathrm{CO}_{2}$ as a working fluid. Appl. Therm. Eng. 2020, 178, 115587. [CrossRef] 